\title{
La formación del talento humano en salud: a propósito del Sistema Nacional de Residencias Médicas en Colombia
}

\author{
The training of health manpower regarding the National Residency \\ System in Colombia
}

Herney Andrés García-Perdomo

Profesor Asociado - Director Posgrado en Ciencias Clínicas, Universidad del Valle. Cali, Colombia

Bien se sabe que en Colombia los médicos contamos con pocos cupos para poder cumplir con el sueño de formarnos como especialistas, tanto en universidades públicas como en privadas. Al momento de ser aceptados en una universidad, se evidencian las altas matrículas que se deben pagar en universidades privadas y el escaso auxilio económico dado por el Instituto colombiano de crédito educativo y estudios en el exterior (ICETEX), como parte de la beca-crédito (dos salarios mínimos mensuales, que se desembolsan cada trimestre), donde incluso no todos los estudiantes son beneficiados.

La Organización Panamericana de la Salud, respecto a las residencias médicas en América Latina, generó un documento en 20II, en el que se evidenciaron los salarios por residente para siete países (Argentina, Brasil, Bolivia, Chile, Costa Rica, El Salvador y Uruguay). Estos variaron desde un mínimo de US\$2I2 en Bolivia, hasta un máximo de US\$200o en Chile, con una mediana de US\$96o. Claramente en Colombia no se cuenta con una remuneración mensual para los residentes ${ }^{\mathrm{I}}$.
Desde hace un par de años ha venido gestándose, con el apoyo de varias instituciones [Federación Médica Colombiana (FMC), Asociación Nacional de Internos y Residentes (ANIR), Asociación Colombiana Médica Estudiantil (ACOME), Asociación Colombiana de Facultades de Medicina (ASCOFAME), Asociación Colombiana de Sociedades Científicas (ACSC) y Colegio Médico Colombiano (CMC)], en cabeza del trabajo arduo de algunas personas, el denominado "Sistema Nacional de Residencias Médicas en Colombia”. En la actualidad ya ha sido sancionada por el Congreso de Colombia mediante la ley I9I7 del I2 de Julio de $2018^{2}$.

En síntesis, el documento expresa los puntos más relevantes que deben darse para garantizar la remuneración adecuada y necesaria de los residentes en Colombia. Algunos de los puntos relacionados con el contrato especial son los siguientes:

- Remuneración mensual no inferior a tres salarios mínimos mensuales legales vigentes.

- Garantía de condiciones y recursos para el desarrollo formativo adecuado.

Palabras clave: cirugía general; educación médica; programas de postgrado; derecho sanitario; legislación médica. keywords: general surgery; education, medical; health postgraduate programs; health law; legislation, medical.

Fecha de recibido: 10/06/2018 - Fecha aceptación: 12/06/2018

Correspondencia: Calle 4b \# 36 - 00, Correo electrónico: herney.garcia@correounivalle.edu.co

Citar como: García-Perdomo HA. La formación del talento humano en salud: a propósito del Sistema Nacional de Residencias Médicas en Colombia. Rev Colomb Cir. 2018;33:244-5. https://doi.org/10.30944/20117582.66 
- Afiliación a los sistemas de salud y riesgos laborales.

- Receso remunerado por el periodo que la Universidad contemple, sin exceder I5 días hábiles por año.

- Plan de trabajo de acuerdo con el establecido por el programa académico y acorde con la Institución Prestadora de Servicios de Salud (IPS).

- Sostenimiento a cargo de la IPS que defina la universidad como escenario base del programa, cuando se encuentren diferentes escenarios de práctica.

- Todo estará en el marco del Decreto 2376 de 2010 que regula y el convenio entre las universidades y las IPS.

En cuanto a la financiación, se establece que estará a cargo de la Administradora de los Recursos del Sistema General de Seguridad Social en Salud (ADRES). Estos recursos serán girados a la IPS base con destinación exclusiva de pago a los residentes. Estos provienen de:

- Aquellos recursos para financiar la becacrédito.

- Hasta un 0,5\% de los recursos de la cotización de recaudados para el régimen contributivo de salud del Sistema General de Seguridad Social en Salud.

- Los excedentes del Fondo de Solidaridad, Fomento al Empleo y Protección al Cesante (FOSFEC).

- Otros recursos que se definan para dicho propósito.

Por otro lado, en esta ley se establece una regulación en las matrículas de las especializaciones médicas; se consideró que no podrá exceder el total de los costos administrativos y operativos que se requieran para el programa académico por parte de la universidad. Adicionalmente, las IPS y las Empresas Sociales del Estado (ESE) no podrán cobrar dinero a las universidades por permitir el desarrollo de la práctica formativa.
Cabe resaltar que los diferentes elementos descritos en la ley son fundamentales y bien merecidos por los estudiantes de posgrados en las diferentes ciencias clínicas del país, con pago de tres salarios, vacaciones pagas y trabajo acorde con la ley, lo cual es prioritario para el desarrollo personal y profesional de nuestros colegas y sus familias. Sin embargo, en la actualidad aún hay dudas respecto a la aplicabilidad de la misma, pues la coordinación de los diferentes estamentos debe establecerse de manera expedita con un sistema que fluya y permita al gobierno nacional, conocer los estudiantes tan pronto son admitidos a las universidades, sus sitios de práctica base y el reconocimiento fácil de su continuidad en el programa. Adicionalmente, deben existir mecanismos de control para establecer el pago fijo, juicioso y continuo desde la IPS de base a los residentes. Por otro lado, debe verificarse el tipo de contratación que se ofrezca, sin que se afecte el objeto primario del estudiante, que es la formación de calidad en el área disciplinar específica, no el trabajo en una IPS. De igual forma, el gobierno nacional deberá hacer un seguimiento exhaustivo para certificar que los valores de las matrículas sean acordes con lo expresado en la ley.

Se ha logrado mucho a favor de nuestros colegas residentes con la unión de diferentes estamentos a los que estaremos agradecidos, pero aún debemos continuar trabajando para que se lleve a buen término este gran sueño de todos.

\section{Referencias}

I. Organización Panamericana de la Salud. Residencias médicas en América Latina. Organización Panamericana de la Salud, editor. Washington: Organización Panamericana de la Salud; 20II.

2. Senado y Cámara de Representantes. Texto definitivo aprobado en sesión plenaria al proyecto de ley 26I de 2017 Senado, 272 de 20I7 Cámara [Internet]. Fecha de consulta: 26 de julio de 20I8. Disponible en: http://es.presidencia. gov.co/normativa/normativa/LEY\%201917\%20 DEL\%2012\%2oDE\%20JULIO\%2ODE\%2020I8.pdf 